\title{
Investigation on Surface Contamination Performances of Outdoor Polymer Insulator Aged by Artificial Acid Rain
}

\author{
Member \\ X. Wang \\ (Akita University) \\ Student Member \\ S. Kumagai \\ (Akita University) \\ Student Member \\ K. Kobayashi \\ (Akita University) \\ Member \\ N. Yoshimura \\ (Akita University)
}

\begin{abstract}
Acid rain is one of the more serious environmental contaminations. Some research results have shown the influence of acid rain on the tracking resistance of outdoor polymer insulating materials. The degradation effects of acid rain on the outdoor composite insulators of silicone rubber and Ethylene Vinyl Acetate (EVA) are investigated by the accelerating aging of artificial acid rain in this paper. Based on the investigation of acid rain, the artificial acid rain is chosen to agree well with the actual ingredients of precipitation. Furthermore, the influence of hydrophobicity degradation on the surface discharge current of insulators is studied. The relations among the hydrophobicity degradation, micro chemical structure and physical morphology of material surface layer are discussed. Test results show that the insulators suffer a large attack and degradation from acid rain. The surface becomes rough, hydrophobicity decreases and surface discharge current increases. The erosion of acid rain on the insulating materials in power system is larger than that on the outdoor materials for the other purposes. Silicone rubber shows a larger resistance against acid rain than EVA.
\end{abstract}

Keywords: Acid Rain, polymer insulator, aging, degradation, hydrophobicity, discharge current

\section{Introduction}

The polymer insulating materials have a wide use in the power system for their better dielectric properties, light weightiness, economic benefits and contamination performance. However, the outdoor HV insulating materials could be aged by environmental stress such as heat, sunlight, moisture, and contamination so that the surface tracking, erosion and discharge may occur, leading to breakdown or flashover $[1,2,3]$.

Along with the development of industry, the environment contamination has become more and more severe. Acid rain is one of the more serious environmental contaminations with social effects. As known from the earlier research, acid rain causes the destruction of the forest, decreases the lifetime of buildings and bridges made of stone and steel, and increases the acidity of earth and water to lead to the ecological disturbance [4]. And in recent years, its influence on the outdoor polymer insulating materials has aroused the interests of power system.

Though there have been some investigations on the effects of acid rain on the insulating materials $[5,6]$, the mechanism and extent of influence on materials are not yet known, for there exist a considerable variety of polymers and their micro chemical and physical structures are very sophisticated. The influences of $\mathrm{pH}$ value, conductivity and the ingredients of acid rain remain to be resolved. It is necessary that the artificial acid rain be chosen to be the same as the actual one so that the results of accelerating aging from laboratory will make progress for the research on the outdoor insulating materials against acid rain.

Our previous researches have shown that acid rain has a large erosion and degradation effect on the tracking resistance of outdoor polymer insulating materials [5]. In this paper, the degradation effects of acid rain on outdoor composite insulators with silicone and EVA rubber bushings are investigated by the accelerating aging of artificial acid rain. The surface discharge current of insulator is studied by Salt Fog Method in a fog chamber. The hydrophobicity of the sample is measured by means of contact angle. The micro surface structure of the material is studied by Metalloscope.

\section{Experiments}

\subsection{Investigation and Preparation of Acid Rain}

Generally speaking, due to the dissolution of carbon oxide in atmosphere into rain water, the normal and clean precipitation becomes acid rain. At $0^{\circ} \mathrm{C}$, under one atm pressure, and with carbon oxide in saturation, the $\mathrm{pH}$ value of normal precipitation is about 5.6. Acid rain is the one with $\mathrm{pH}$ value lower than 5.6. The sulfur oxide $\mathrm{SO}_{x}$, nitro oxide $\mathrm{NO}_{x}$ and the other contaminants in atmosphere dissolve into rain to become sulfuric acid, nitric acid and the other sorts of acid $[4,7]$.

As is known to all, acid rain mainly results from the use of coal and heavy oil fuels, the exhaust of car and the other origins 
Table 1. The ion deposition of atmosphere in Japan [7] Unit: $\mathrm{g} / \mathrm{m}^{2}$

\begin{tabular}{|c|c|c|c|c|c|c|c|}
\hline & Prec. & $\mathrm{H}^{+}$ & $\mathrm{SO}_{4}{ }^{2-}$ & $\mathrm{NO}_{3}{ }^{-}$ & $\mathrm{NH}_{4}^{+}$ & $\mathrm{Ca}^{2+}$ & $\mathrm{nss}-\mathrm{SO}_{4}{ }^{2-}$ \\
\hline $\operatorname{Max}$ & 2.041 & 0.061 & 5.04 & 2.53 & 1.00 & 1.18 & 4.78 \\
\hline Wet Min & 590 & 0.002 & 1.08 & 0.19 & 0.02 & 0.15 & 0.45 \\
\hline Av. & 1.403 & 0.024 & 3.00 & 1.20 & 0.47 & 0.43 & 2.51 \\
\hline $\operatorname{Max}$ & - & - & 2.00 & 0.79 & 0.43 & 1.51 & 1.89 \\
\hline Dry Min & - & - & 0.22 & 0.05 & 0.01 & 0.01 & 0.06 \\
\hline Av. & - & - & 0.72 & 0.34 & 0.08 & 0.38 & 0.60 \\
\hline
\end{tabular}

Note: 1 . The average is the weighted average by the precipitation per annual in 1989-1992.

2. Wet Deposition is the ingredient density of ion multiplied by precipitation.

Table 2. The ingredients density of ion in precipitation [7] Unit: $\mathrm{mg} / \mathrm{l}$

\begin{tabular}{|c|c|c|c|c|c|c|c|c|}
\hline & Prec. & $\mathrm{H}^{+}$ & $\mathrm{SO}_{4}{ }^{2-}$ & $\mathrm{NO}_{3}{ }^{\circ}$ & $\mathrm{NH}_{4}{ }^{+}$ & $\mathrm{Ca}^{3+}$ & nss-SO ${ }_{4}^{2}$ & nss- $-\mathrm{Ca}^{2+}$ \\
\hline Max & 5.8 & 0.032 & 3.60 & 1.55 & 0.54 & 0.75 & 2.83 & 0.69 \\
\hline Min & 4.5 & 0.002 & 0.99 & 0.11 & 0.01 & 0.10 & 0.22 & 0.04 \\
\hline Av. & 4.8 & 0.017 & 2.13 & 0.87 & 0.33 & 0.32 & 1.85 & 0.28 \\
\hline
\end{tabular}

Note: 1 . The average is the weighted average by the precipitation per annual in 1989-1992.

2. nss- is the abbreviation of non-sea-salt.

of industrial pollution. The exhausted contaminants react with the oxygen in atmosphere by UV ray, and then dissolve into rain. Because of the dispersion, turbulent flow, and transformation of gas contaminants in the atmosphere, acid rain may exist where the contaminant source is far away. It is well known that the social effect of acid rain is international [4].

There are two types of the chemical contaminants from the atmosphere. One is the wet deposition in all the precipitations, including rain, snow, fog and frost. Another is dry deposition which appears in the form of gas and aero gel. Table 1 is the ion deposition of atmosphere in Japan [7]. The acid rain includes wet and dry depositions. The tracking phenomena of outdoor insulating materials actually has relations with two depositions.

The ingredients of acid rain mainly consist of ions such as $\mathrm{SO}_{4}{ }^{2-}, \mathrm{NO}_{3}{ }^{-}, \mathrm{NH}_{4}{ }^{+}, \mathrm{Ca}^{2+}, \mathrm{Cl}, \mathrm{K}^{+}, \mathrm{Mg}^{2+}, \mathrm{Na}^{+}$, et al. The composition and density of the ion ingredients in the annual precipitation of Japan are shown in Fig.1 and Table 2, respectively [7]. According to the investigation of Meteorology Bureau of Japan, the $\mathrm{pH}$ value of acid rain increases annually. The average of $\mathrm{pH}$
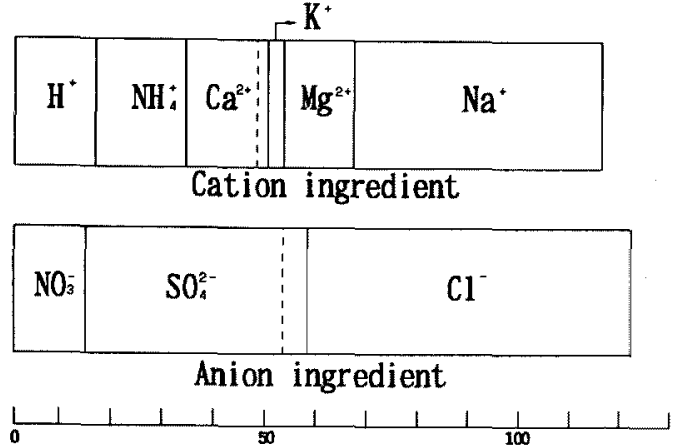

Fig.1 The composition of ion ingredients density in the annual precipitation [7]. Unit: $\mu \mathrm{g} / \mathrm{l}$

Table 3. Ingredients of artificial acid rain used in this experiment. Unit: $\mathrm{g} / 2 \mathrm{l}$

\begin{tabular}{l|c}
\hline Ingredients & Contents \\
\hline $\mathrm{NH}_{4} \mathrm{Cl}$ & 1.00 \\
$\mathrm{NaCl}$ & 2.55 \\
$\mathrm{KCl}$ & 0.18 \\
$\mathrm{HNO}_{3}$ & 0.90 \\
$\mathrm{MgSO}_{4}$ & 1.05 \\
$\mathrm{CaSO}_{4} \cdot 2 \mathrm{H}_{2} \mathrm{O}$ & 0.90 \\
\hline
\end{tabular}

value in Honshu of Japan in 1992 is 4.8 .

In view to the influence of acid rain on materials, the main characteristics of acid rain are the $\mathrm{pH}$ value, ion ingredients and conductivity. The three essential factors are related to each other. It is the ingredients and composition of acid rain that decide the $\mathrm{pH}$ value and conductivity. In this research, the choice of artificial acid rain solution is to lay stress on the main ingredient, and $\mathrm{pH}$ value of the actual acid rain. The composition of artificial acid rain in Table 3 is decided according to the research results in Table 1, 2 and Fig.1, and agrees with the actual one. In our accelerating aging experiment, the ingredients of artificial acid rain is 500 times as great as the actual acid rain. The $\mathrm{pH}$ value of artificial acid rain solution is 2.1 and its conductivity is $7000 \mu \mathrm{S} / \mathrm{cm}$.

\subsection{Study of Surface Appearances and Hydrophobicity}

The hydrophobicity plays an important part in the tracking resistance and contaminant characteristic of insulation surface The superior contaminant performances of polymer outdoor insulating materials are regarded as the contribution of their hydrophobic surfaces. Surface hydrophobicity of materials has some relations not only to the surface appearance such as smooth and pollution level, but also to the inherence of material, i.e. the binding energy and surface energy, as well as the micro physical morphology and chemical structure of material. The contact angle 


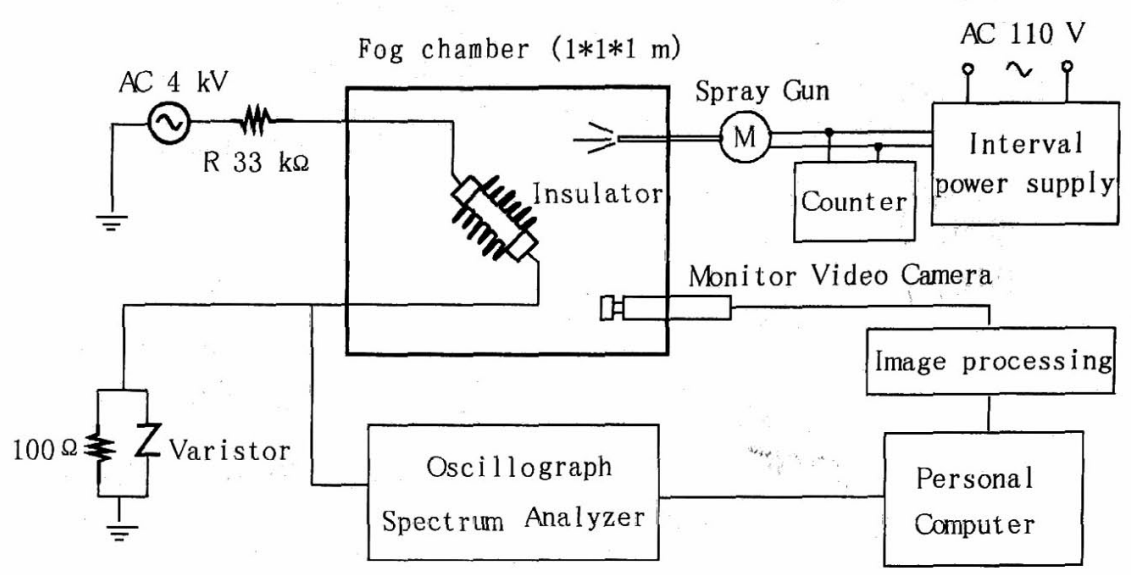

Fig.2 Experimental diagram of fog chamher

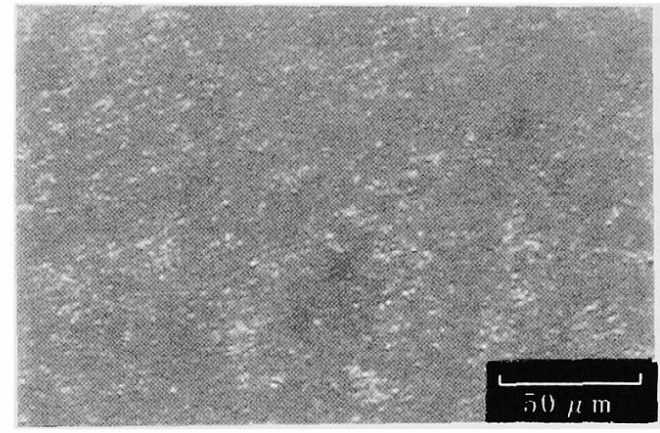

(a) Origin

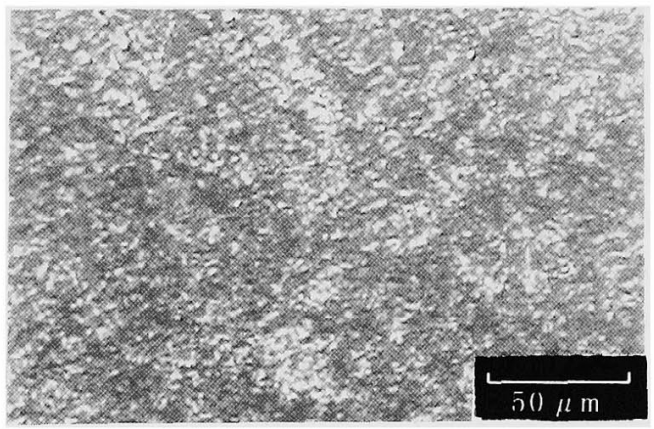

(b) Soak-aged for 60 days

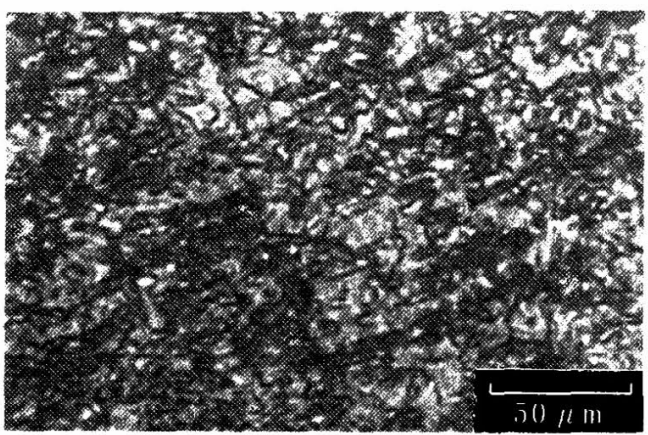

(c) Energized-aged for 10 days

Fig.3 Metalloscope picture of silicone rubber insulator

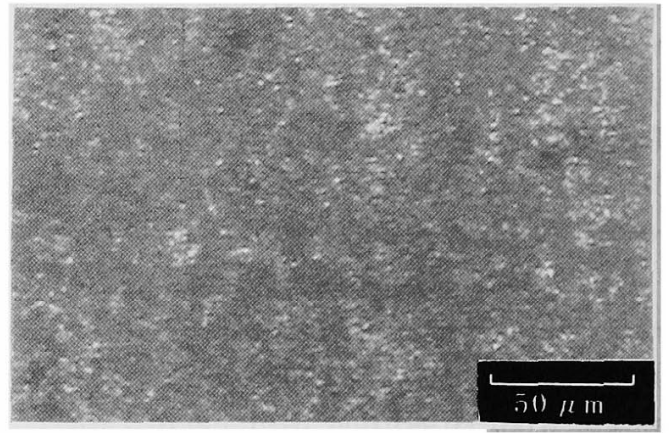

(a) Origin

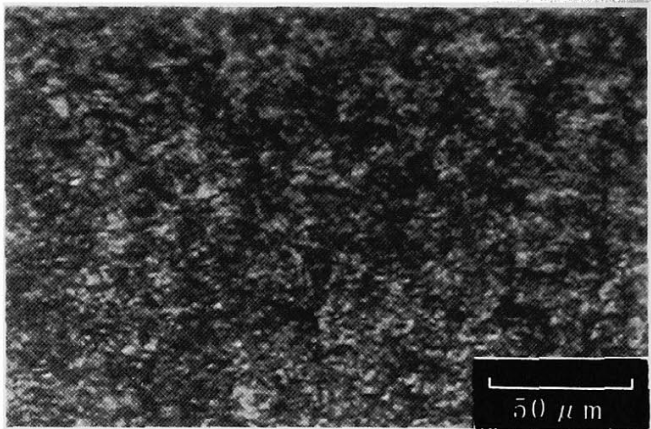

(b) Soak-aged for 60 days

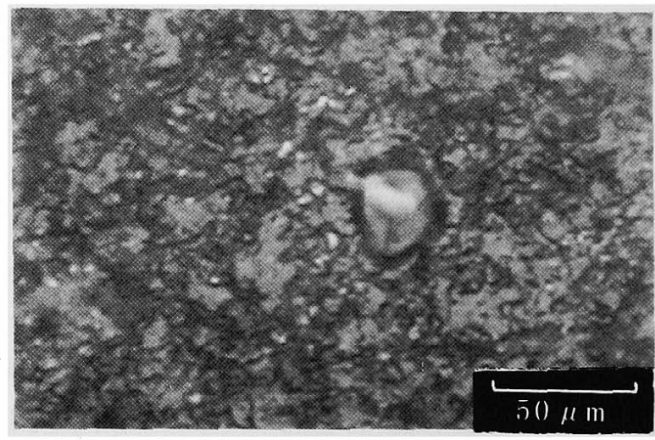

(c) Energized-aged for 10 days

Fig.4 Metalloscope picture of EVA insulator 


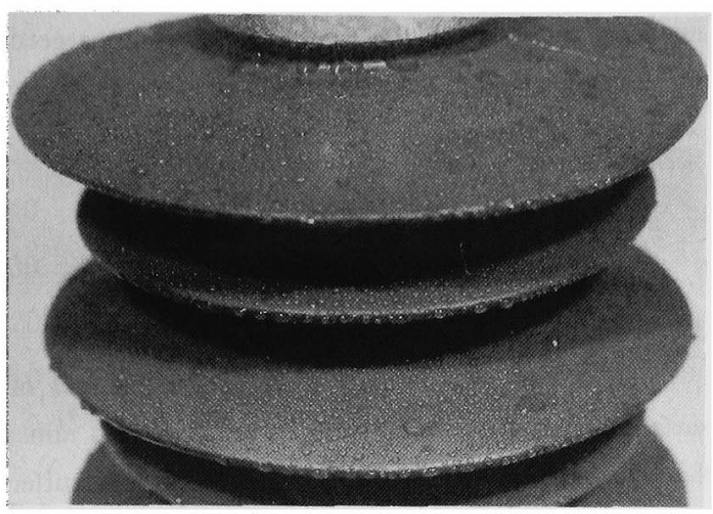

(a) Origin

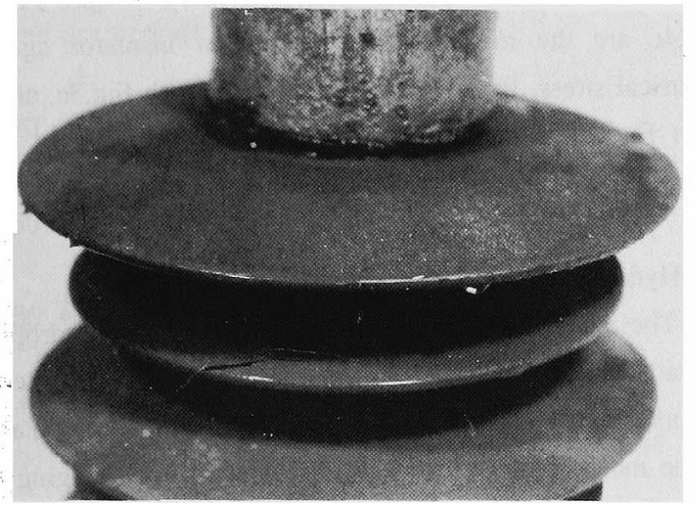

(b) Soaked-aged for 60 days

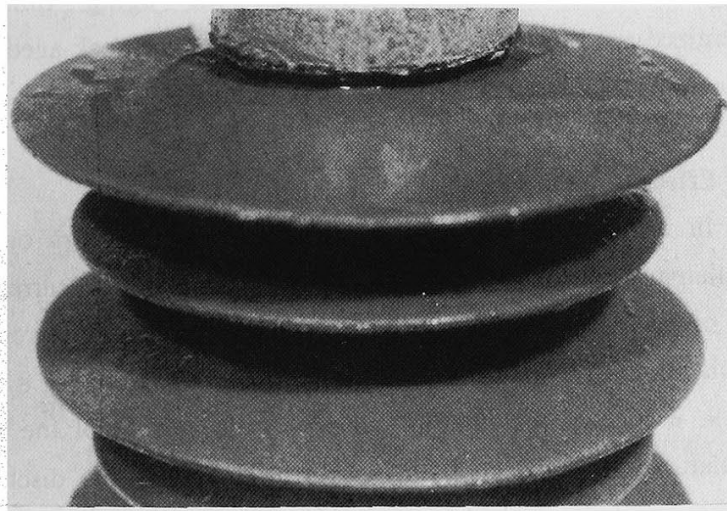

(c) Energized-aged for 10 days

Fig.5 Surface hydrophobicity of silicone rubber insulator

of material, surface is used to show hydrophobicity. The metalloscope is applied to study the surface appearances of material.

\subsection{Salt - Fog Test}

Salt Fog method is used to investigated the surface discharge current of the insulator. The salt fog test is carried out in $1 \times 1 \times 1$ $\mathrm{m}^{3}$ fog chamber. The diagram of experiment system is shown in Fig.2. The insulator is mounted at an angle of $45{ }^{\circ}$ to the horizontal in order to make salt fog wet the underside of shed. Salt fog is generated by a spray gun with an interval power source. Salt fog flow rate is $5 \mathrm{ml} / \mathrm{min}$. The test cycle is designed

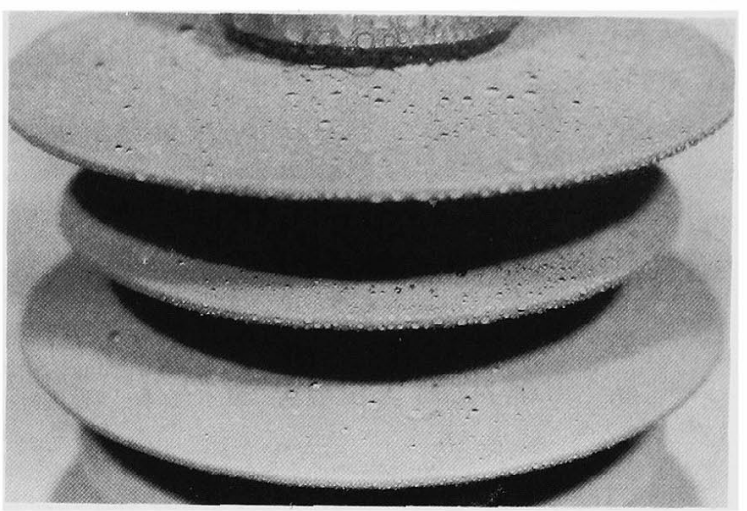

(a) Origin

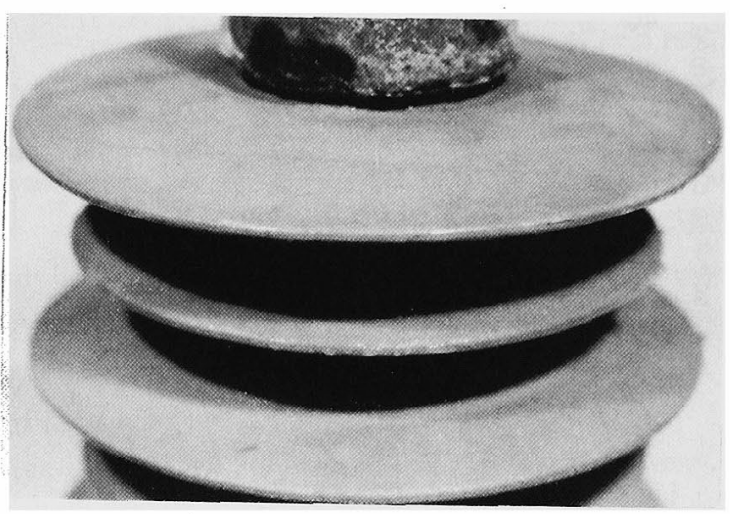

(b) Soaked-aged for 60 days

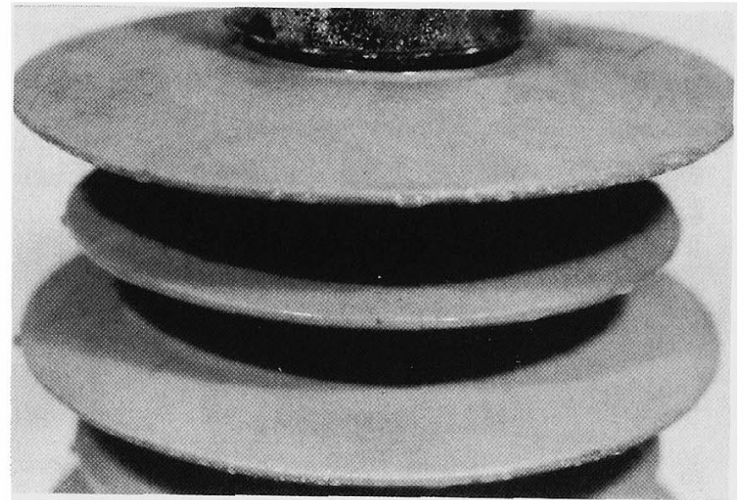

(c) Energized-aged for 10 days

Fig.6 Surface hydrophobicity of EVA insulator

as $30 \mathrm{~s}$, with $10 \mathrm{~s}$ wet and $20 \mathrm{~s}$ dry. The measured discharge current of insulator is the average in wet and dry periods of the test cycle. The resource of salt fog, i.e. the test contaminant fog is $0.5 \% \mathrm{NaCl}$ solution. Its conductivity is $10000 \mu \mathrm{S} / \mathrm{cm}$ and $\mathrm{pH}$ value is 5.2 , much weaker than that of artificial acid rain.

\subsection{Soak-aging and Energized-aging}

Among the composite insulating materials for outdoor applications, silicone rubber and EVA find the widest use. In our research, Silicone rubber and EVA insulators of $6 \mathrm{kV}$ outdoor type are taken as samples. The flashover distance of the insulators is $210 \mathrm{~mm}$, and surface leakage distance is $550 \mathrm{~mm}$. 


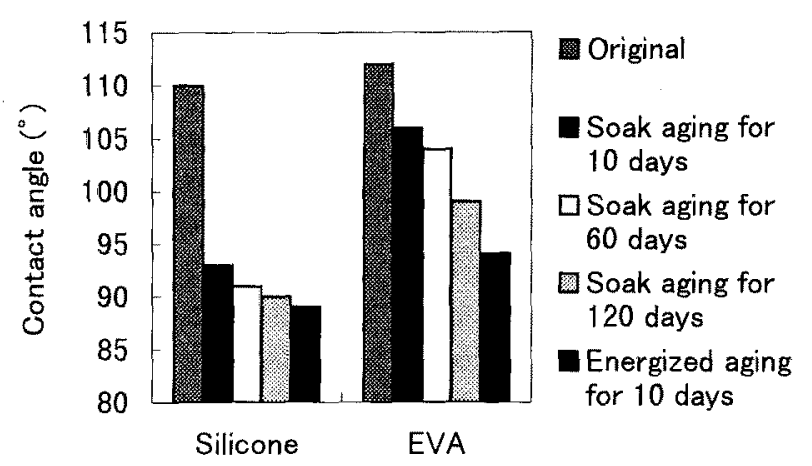

Fig.7 The contact angle of insulators before and after aging

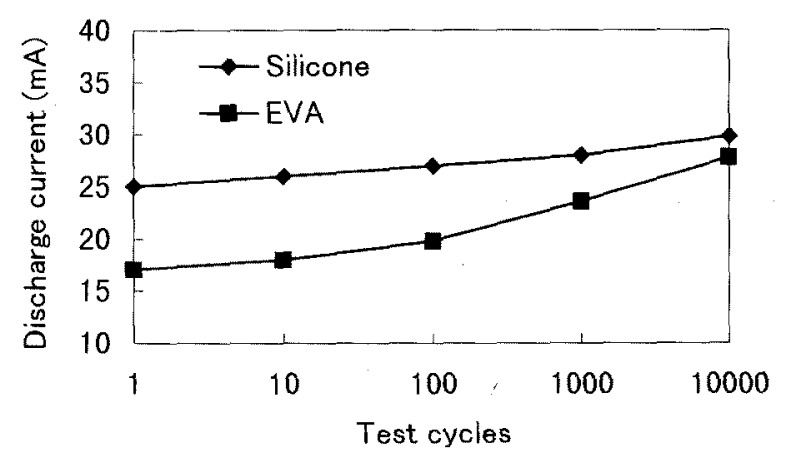

Fig. 8 The surface discharge current of original insulator

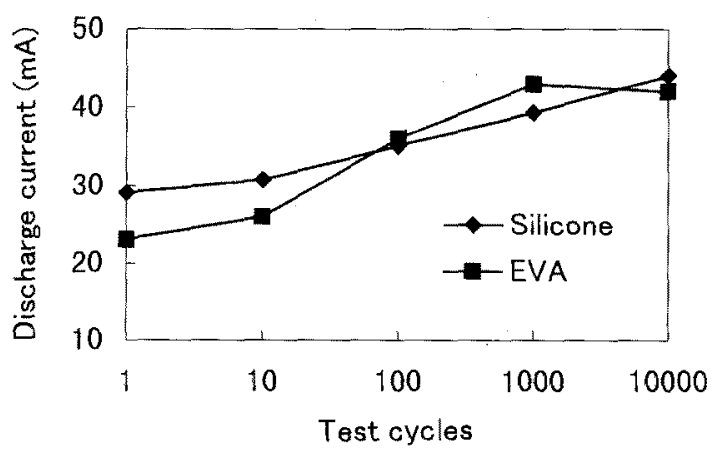

Fig. 9 The surface discharge current of insulator soak-aged for 30 days

$4 \mathrm{kV} \mathrm{AC}$ voltage, the same as the working voltage of the selected insulator, is applied to the samples, i.e. the applied electrical stress on the insulator surface is $8 \mathrm{kV} / \mathrm{mm}$. in fact, outdoor insulating materials suffer from environmental stress under working voltage. In order to investigate the degradation effect of acid rain on insulating materials under electrical stress, two aging procedures are used. One is the soak-aging that insulator sample is soaked in the solution of acid rain for some days without applying voltage. The other is the energized-aging that the insulator is aged in the fog of artificial acid rain under the $4 \mathrm{kV}$ working electrical stress in fog chamber, i.e. we use the artificial acid rain to take the place of $\mathrm{NaCl}$ solution as the contaminant in Fog Chamber test to simulate the actual energized-aging of insulator in field. The discharge current and surface degradation of the energized-aged insulator are compared with those of the soak-aged one

\section{Experimental Results}

\subsection{Insulator Surface Appearance}

Fig.3 and Fig.4 are the metalloscope pictures of insulator surface before and after soaking in artificial acid rain. It is clear that the surface of material aged in acid rain suffers a large erosion and attack. Due to the erosion and degradation effect of acid rain, material surface becomes more rough. Fig. $3 \mathrm{c}$ and Fig. $4 \mathrm{c}$ are the metalloscope pictures of insulator aged under electrical stress. By comparison of Fig.3b with Fig.3c, and Fig.4b with Fig. $4 c$, we can see that insulating materials in electrical stress more easily suffer from acid rain.

\subsection{Hydrophobicity Degradation}

The pictures in Fig.5 and Fig.6 show the hydrophobicity degradation of the insulator. The measured contact angles before and after aging in acid rain are shown in Fig.7. The contact angle of the materials decreases in some extent with the aging time. It is obvious that after aging in acid rain, material surface suffers a large erosion and attack. Though the aging time of energized-aged insulator is shorter than that of the soak-aged one, its contact angle decreases much more than that of the soak-aged.

\subsection{Effect of Acid Rain on the Discharge Current}

In the dry condition, no discharge current occurs on the insulator surface. Fig.8 shows the average discharge current of the original insulator. Fig. 9 is the average discharge current of insulator soak-aged in acid rain. By comparison of Fig. 8 with Fig.9, it is seen that the surface discharge current of the aged insulators increases largely. As shown in Fig.10, the discharge current increases with the aging time. From the test results, we can see that under the aging of acid rain, the discharge current of EVA insulator increases more rapidly than that of silicone, that is, EVA suffers easily from acid rain.

\subsection{Effects of the Energized-aging}

Fig. 11 shows the discharge current of the insulator aged in the fog of artificial acid rain under electrical stress for 10 days. It is clear that the average discharge current of this energized-aged insulator is larger than that of the insulator soak-aged in the solution of acid rain as shown in Fig.9. Fig.12 is the average discharge current of the insulator in the energized-aging process. By comparison of Fig. 12 and Fig.8, we can see that the surface discharge current of the insulator increases substantially. Fig.13 is the relation of average discharge current of the energized-aged 


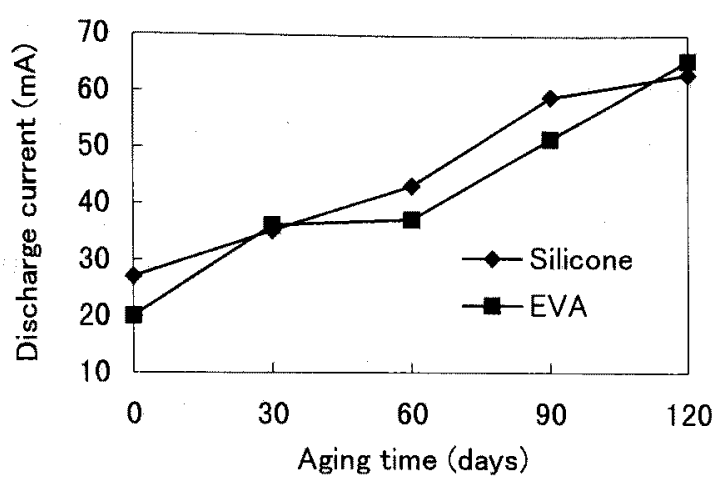

Fig.10 The relation of surface discharge current of the soak-aged insulator to the aging time. The discharge current is the average of wet and dry periods of the 100th test cycle.

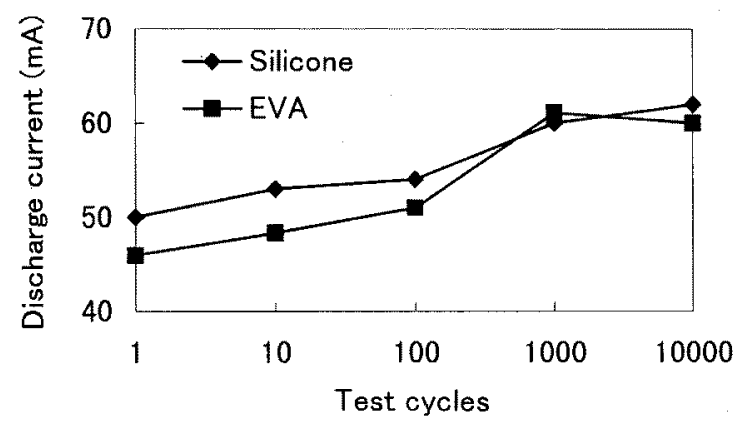

Fig.11 The surface discharge current of the insulator energized-aged for 10 days

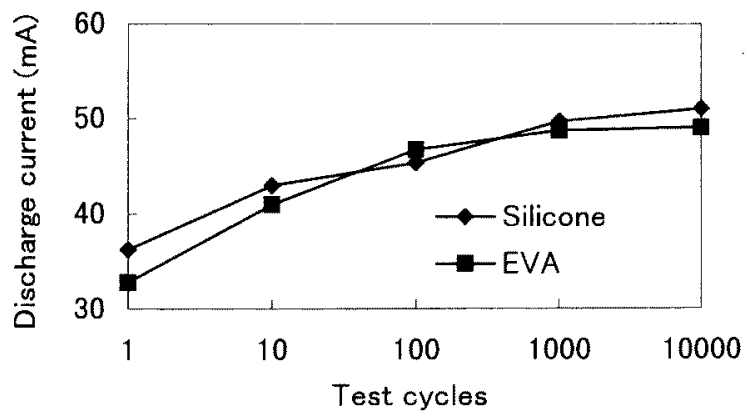

Fig. 12 The surface discharge current of insulator in the energized-aging process

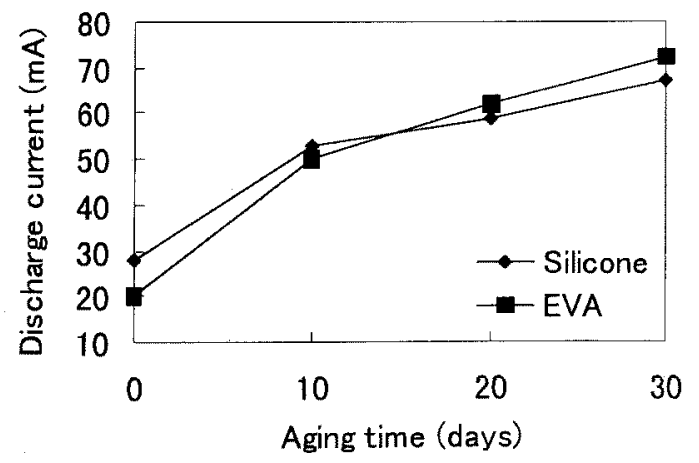

Fig.13 The relation of surface discharge current of energizedaged insulator to the aging time. The discharge current is the average of wet and dry periods of the 100th test cycle. insulator to the aging time. Compared with the results of the soak-aged insulator in Fig.10, in the same aging period, the degradation of the energized-aged insulator is larger than that of the soak-aged insulator, which implies that electrical stress plays an important accelerating role in the degradation effect of acid rain on the outdoor polymer insulating materials.

\section{Discussion}

\subsection{Mechanism of Acid Rain Degradation}

The metalloscope results have shown the erosion effect of acid rain on the materials. The contact angles of the materials almost decrease with soaking time in the solution of acid rain in some extent. It is clear that after aging in the solution of acid rain, the material surface suffers a large erosion and attack. There are some defects on the surface. These show that due to the erosion and degradation effect of acid rain, surface of the material becomes more rough and hydrophobicity decreases. Therefore, the contaminant performances of materials degrade. The reduction of surface hydrophobicity leads to the initiation of tracking phenomena and the increasing of discharge current.

The most severe influence of acid rain on the materials is the erosion effect. Generally speaking, it is the acid anhydride in acid rain that attacks the unsaturated double-bond group and the weak link of the macro molecular. The macro molecules break into small molecules or free terminals and radicals to initiate the chain reaction. The polymer degrades in succession so that the low density area is formed and micro defects occur on the surface.

On the other hand, the disruption of chemical structure, formation of low density and micro pores in the surface layer of material will decrease the material binding energy and increase surface energy so that the surface hydrophobicity decreases [8]. Moreover, the degradation of materials surface layer will result in the reduction of contaminant resistance of surface layer, which could aggravate the erosion of acid rain on material furthermore.

\subsection{Resistance of Insulating Materials to Acid Rain}

The resistance of outdoor insulating materials to the erosion of acid rain is different from the outdoor materials for other purposes. This is because the materials for other applications are not considered to have electrical insulating properties. They have proper acid-fast fillers in and work without electrical stress

The experimental results have shown the degradation effects of acid rain on the insulating materials aged under voltage. The erosion and degradation of acid rain under voltage are much more than those without voltage. The most severe influence of acid rain on the materials is the erosion effect. Insulating materials work under the electrical stress. The electrical stress 
plays an accelerating role in the erosion and aging of acid rain. The erosion 'of acid rain on insulating materials under electric stress is the electrochemical corrosion, just like the electrolyte process. This implies that insulating materials should have larger resistance than other materials to acid rain. What is more important, the tracking and discharge phenomena may occur on the surface of insulating materials under the aging of acid rain.

As is known, the insulation coordination sequence of insulating materials in power equipment and apparatus is decided by the heat resistance of materials. And the tracking resistance of materials mainly depends on heat resistance. The resistances of insulating materials to acid rain should agree with their heat resistances. The atom bond structure of silicone rubber is of hydrophobic and $\mathrm{Si}-\mathrm{O}$ bond energy is so high that the Silicone rubber has high heat resistance and its resistance to acid rain is larger than EVA. Though it seems that the hydrophobicity of EVA is higher than that of silicone rubber, because the $\mathrm{C}-\mathrm{H}$ bond in it is weak to resist the attack of acid, EVA is easily to suffer from acid rain.

\section{Conclusions}

The investigation shows that acid rain has a large erosion effect on the outdoor polymer insulator. The chemical structure and physical morphology of surface layer degrade and the insulator surface becomes rough so that surface hydrophobicity decreases, and the discharge current increases. Silicone rubber shows a larger resistance against acid rain than EVA. Because of its $\mathrm{C}-\mathrm{H}$ structure, EVA suffers from acid rain more easily than silicone rubber.

\section{Further Work}

In our present research, we noticed that after some rest in dry condition, the hydrophobicity of the aged silicone insulator is restored to some extent, and that the discharge current decreases. These phenomena will be taken into account from now on.

(Manuscript received Sept. 3, 1997; revised Dec. 15, 1997)

\section{References}

[1] W. T. Star, "Polymer Outdoor Insulation," IEEE Trans. Electr. Insul., Vol. 25, pp. 125-136, 1990.

[2] R. S. Gorur and T. Orbeck, "Surface Dielectric Behavior of Polymeric Insulation under HV Outdoor Conditions," IEEE Trans. Electr. Insul. Vol. 26, pp. 1064-1072, 1991.

[3] I. Urushihara, K. Naito, K. Sakanishi and R. Matsuoka, "A Method of Artificial Contamination Test on Composite Insulators," Proc. 8th ISH, Vol. 2, pp. 209-212, August, 1993.
[4] S. S. Butcher and R. J. Charlson, "An Introduction to Air Chemistry," Academic Press Inc., New York, 1992, Chapter 2-3. [5] N. Yoshimura, A. Shikimura and S. Hasegawa, "The Effect of Acid Rain on the Tracking Resistance of Organic Insulating Materials," IEEJ Trans., Vol. 115-A, pp. 890-895, 1995.

[6] D. Y. Li, S. Hwangbo, D. H. Park, K. S. Suh and M. K. Han, "The Tracking Phenomena and Chemical Degradation of Elastomer Aged by the Acid Rain," Proc. 25th Symp. Electr. Insul. Mat., Nagoya, Japan, pp. 95-100, Sept., 1993.

[7] The Meteorology Bureau of Japan, "The Report of Second Investigation of Acid Rain," Acid Rain Seminar, July, 1994.

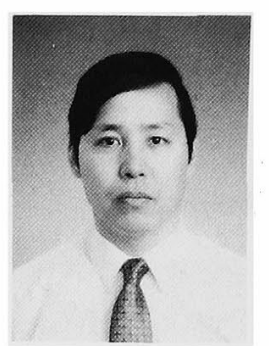

X. Wang (member) He was born in Oct., 1957. He received his B.E. in Electrical Insulation from Xi'an Jiaotong University in 1981; M.E. in HV Eng. from Wuhan Hydraulic \& Electrical Engineering University in 1986; $\mathrm{PhD}$ from Xi'an Jiaotong University in 1992. Now he works in Akita University.

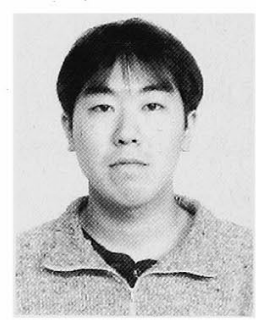

S. Kumagai (Student member) $\mathrm{He}$ was born in July, 1972. He received his B.E. and M.E. in Electrical and Electronic Engineering from Akita University in 1995 and 1997, respectively. $\mathrm{He}$ currently studies on outdoor polymer insulating materials in Akita University as a Doctor course student.

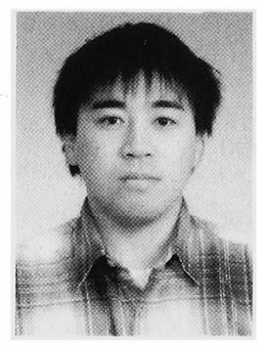

K. Kobayashi (Student member) $\mathrm{He}$ was born in June, 1972. He received his B.E. in Electrical and Electronic Engineering from Akita University in 1996. He currently studies in Akita University as a Master course student.

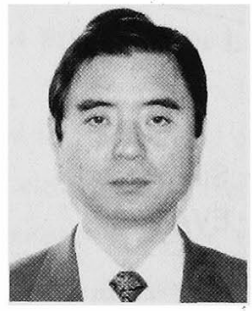

N. Yoshimura (member) He was born in Nov., 1943. He received his B.E. and M.E. in Electrical and Electronic Engineering from Akita University in 1967 and 1969 respectively; $\mathrm{PhD}$ from Nagoya University in 1975 . He joined Akita University in 1969, became professor in 1983, and has been the Dean of Mining College of Akita University since 1995. From Jan., 1978 to Sept., 1979, he worked in Clarkson University of USA as visiting scholar. His research interests include dielectric materials of polymer, ceramics and semiconductive ceramics. 